\title{
Emerging targets to monitor and overcome docetaxel resistance in castration resistant prostate cancer (Review)
}

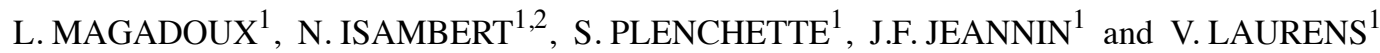 \\ ${ }^{1}$ EA 7269 Ecole Pratique des Hautes Etudes-University of Burgundy-INSERM U866, Dijon; \\ ${ }^{2}$ Centre Georges-François Leclerc, Dijon 21079, France
}

Received January 24, 2014; Accepted March 18, 2014

DOI: 10.3892/ijo.2014.2517

\begin{abstract}
Drug development for castration resistant prostate cancer (CRPC) is challenging, since this cancer is still associated with high mortality and limited therapeutic options. In 2004, docetaxel became the first-line chemotherapy for CRPC improving survival by a few months and remains the standard of care in CRPC patients. However, existing or developing resistance to docetaxel in patients is the main limitation of its efficacy. The present review presents the molecular mechanisms involved in docetaxel toxicity and in docetaxel resistance in prostate cancer cells. We outlined the endogenous mechanisms of resistance and the role of tumor microenvironment in the resistance of CRPC to docetaxel. This has led us to focus on molecules associated with resistance, such as the molecular chaperones heat shock proteins (HSPs) and clusterin (CLU), and the cytokines interleukin-6 (IL-6) and the divergent member of the tumor growth factor family MIC-1 (macrophage inhibitory cytokine-1 also named GDF-15). We discuss their interest as blood-based markers to monitor docetaxel resistance. Finally, new therapies intended to overcome docetaxel resistance of CRPC targeted on these molecular resistance pathways are present.
\end{abstract}

\section{Contents}

1. Introduction

2. Mechanisms of action of docetaxel toxicity in CRPC cells

3. Resistance of CRPC to docetaxel

4. Biological markers of docetaxel resistance

5. New therapies intended to overcome docetaxel resistance of CRPC

6. Conclusion

Correspondence to: Dr Véronique Laurens, Cancer Immunology and Immunotherapy, EPHE, Faculty of Medicine, 7 Boulevard Jeanne d'Arc, Dijon 21000, France

E-mail: veronique.laurens@u-bourgogne.fr

Key words: biological marker, CRPC, docetaxel, MIC-1, protein of resistance, clusterin

\section{Introduction}

The androgen receptors play a central role in prostate cancer development, their activation stimulates proliferation and inhibits apoptosis of prostate cancer cells (1). Androgen deprivation therapy is thus the standard first line treatment for advanced prostate cancer (2). When testicular androgen production is suppressed and/or androgen receptor signaling is prevented, clinical improvement is observed. Unfortunately, these patients invariably relapse and develop castration resistant prostate cancer (CRPC) within 18-24 months (3). Relapse is due to amplification of the expression (4), or to mutations of androgen receptors allowing their activation by progesterone, estrogens (5) and androgen antagonists (6) or to androgen neo-synthesis in prostate tumor or adrenals (7). Furthermore, nuclear factor $\kappa \mathrm{B}(\mathrm{NF}-\kappa \mathrm{B})$ and its target interleukin-8 (IL-8) contribute to androgen-independence of prostate cancer cells by stimulating their proliferation $(8,9)$.

It was shown that docetaxel increases significantly the overall survival (OS) of CRPC patients with 16.5 months in the prednisome plus mitoxantrone group and 18.9 in the prednisone plus docetaxel group (10). The analysis of 12 randomized trials provides evidence of clinical benefit for docetaxel-based combination chemotherapy for CRPC patients (11). Thus, the standard treatment of CRPC patients remains docetaxelbased chemotherapy (12). However, resistance to docetaxel is a significant clinical problem given that about half of patients do not show prostate specific antigen (PSA) response $(10,13)$. They are either spontaneously resistant to docetaxel, or they become docetaxel resistant, but finally and rapidly, the tumor progression goes or comes back in all patients. To bypass this resistance, several new therapies have been developed including cellular immunotherapy or hormonotherapy. But to overcome docetaxel resistance it is critical to precise its molecular mechanisms. Various mechanisms of taxane (docetaxel and paclitaxel) resistance have been studied, but there is no consensus to date regarding a definition of taxane resistance (14).

We reviewed docetaxel resistance in CRPC patients (in vivo) and cell lines (in vitro). We start with a description of mechanisms of action of docetaxel toxicity in CRPC cells, mechanisms of resistance of CRPC to docetaxel, then we provide insight into several biological markers of docetaxel resistance and finally we present new prostate 
cancer therapies proposed to overcome docetaxel resistance.

\section{Mechanisms of action of docetaxel toxicity in CRPC cells}

Docetaxel is known to bind the $\beta$ subunits of tubulin in microtubules, which stabilizes them, inhibits their depolymerization $(15,16)$ blocks mitosis and finally induces apoptosis $(16,17)$. In CRPC cells, docetaxel induces B-cell lymphoma 2 (Bcl-2) phosphorylation that prevents its heterodimerization and leads to caspase activation and apoptosis (18) in vivo and in vitro (19). Apoptosis could be induced via mitotic catastrophe (18) or could be independent (20). Moreover, docetaxel was able to induce apoptosis by nuclear interaction of Smac-DIABLO with survivin (an inhibitor of apoptosis protein, IAP, that regulates the cell cycle) (21).

In addition, docetaxel reduces the expression of androgen receptor on CRPC cells (22) and its mechanism of action seems to involve androgen receptor (AR) nuclear localization and signalling inhibition.

\section{Resistance of CRPC to docetaxel}

Prostate cancer cell population is heterogeneous, including stem cells or neuroendocrine cells, and either uses multiple mechanisms of resistance at the same time, leading to selection of docetaxel resistant cells or is modified by docetaxel to become resistant. To study docetaxel resistance, human prostate cancer parental cells and their docetaxel-resistant derived cell lines are currently used, as the androgen-dependent cell line LNCaP, or the androgen-independent cell lines, PC3, DU145 and 22RV1.

Resistance of CRPC to docetaxel can be related to endogenous cell mechanisms by production of secreted clusterin (CLU) for example or to characteristics of the tumour microenvironment, as hypoxia.

Endogenous CRPC cell mechanisms of resistance to docetaxel. Some mechanisms of docetaxel resistance in prostate cancer include constitutive production of molecules as multidrug resistance proteins, p53, CLU. Some of these proteins may be mutated (p53, Bax) or overexpressed [class III $\beta$-tubulin, protease-activated receptor 1 (PAR1 or thrombin receptor)]. Furthermore, proteins constitutively expressed as CLU can be overexpressed by stress signal and create a positive loop with enhanced AKT signaling pathway. The ways of docetaxel resistance in CRPC cells are thus numerous and cross overs exist (23). We spotlight below mechanisms involving drug efflux, drug target, apoptosis, survival pathways, inflammation mediators, as cytokines or chemokines and chaperone molecules.

Drug efflux. Multidrug resistance proteins (MDRP) including P-gp (P-glycoprotein), MRP1 (multidrug resistance-associated protein 1) and BCRP (breast cancer resistance protein), act as pumps of drug efflux with a wide range of substrates including docetaxel, and in various tissues including prostate cancer cells. In CRPC patients receiving docetaxel, MDR1 genetic variations are associated with docetaxel resistance (24). P-gp is not expressed in PC3 cells, while DU145 and 22RV1 docetaxel-resistance derived cell lines, overexpress P-gp by comparison with parental cells, and inhibition of P-gp restores their reactivity to docetaxel (25). In addition, docetaxel resistance can be induced by phosphorylation of BCRP by serine/threonine kinase PIM-1 in CRPC cells (26).

Drug target. By targeting $\beta$-tubulin, docetaxel can block CRPC cell mitosis (see above). Moreover, class III $\beta$-tubulin isoform, that reduced taxane binding, is highly upregulated in CRPC cells (27). The overexpression of this isoform confers docetaxel resistance to CRPC cells and inhibiting class III $\beta$-tubulin expression increases their sensitivity to docetaxel (28). Impaired tubulin polymerization by docetaxel can also be evidenced in an LNCaP derived docetaxel-resistant cell line and explained by an F270I mutation in class I $\beta$-tubulin (29).

Blocking apoptosis. p53 protein by regulating the cell cycle and apoptosis plays a key role in docetaxel resistance. It is frequently overexpressed in prostate cancer, which is often associated with mutations (30). LNCaP cells (bearing wild-type p53) are more resistant to docetaxel than DU145 (bearing mutant p53) and PC3 (lacking p53) cells. Knocking down p53 sensitizes LNCaP cells to docetaxel, indicating that p53 is involved in docetaxel resistance in prostate cancer cells (31).

Bcl-2 mutation is an extremely rare event in prostate cancer. However, it is shown in CRPC that missense mutation affecting the BH3 domain of Bax is involved in the formation of Bax-Bax and Bax-Bcl-2 dimers (32). It is, therefore, possible that the pro-apoptotic activity of Bax-Bax dimer is lost. Modulation of the expression of Bcl-xL, an anti-apoptotic member of the Bcl-2 family, in PC3 cells renders cells more or less resistant to docetaxel, showing that resistance of these cells to docetaxel is linked to Bcl-xL level of expression (33).

In addition, activation of PAR 1 decreases docetaxel induced apoptosis through $\mathrm{NF}-\kappa \mathrm{B}$ activation and the upregulation of Bcl-xL (34). PAR1 is overexpressed in prostate cancer and its ligand thrombin is also overexpressed in prostate cancer patients (34), thus, this signaling pathway could be involved in vivo in the resistance to docetaxel.

Survival pathways. By itself, docetaxel can induce survival pathways. Indeed, the binding of docetaxel to $\beta$-tubulin induces a stress signal that in return activates different survival signaling pathways such as c-Jun N-terminal kinase (JNK), leading to transcription factor activation as signal transducers and activator of transcription-1 (STAT-1), STAT-3, NF- $\kappa$ B. STAT proteins are a family of transcription factors that regulates gene expression to influence differentiation, proliferation, apoptosis and angiogenesis. STAT-1 is involved when DU145 and PC3 CRPC cells are made resistant to docetaxel and this is CLU-dependent (35). Furthermore, STAT-3 is also implicated in the resistance to docetaxel but via the serine-threonine kinase PIM1 that improves the survival of DU145 cells treated with docetaxel (36).

$\mathrm{NF}-\kappa \mathrm{B}$ in the cytoplasm is inhibited by I $\mathrm{B}-\alpha$. Upon stimulation of $\mathrm{I} \kappa \mathrm{B}$ kinases (IKK), I $\mathrm{B}$ - $\alpha$ is degraded leaving $\mathrm{NF}-\kappa \mathrm{B}$ free to translocate to the nucleus and activate a wide variety of survival genes. $\mathrm{NF}-\kappa \mathrm{B}$ is activated constitutively through IKK activation in both DU145 and PC3 cells but not in LNCaP cells (37-39). The constitutive activation of $N F-\kappa B$ 
prevents the cytotoxic activity of docetaxel, since its inhibition increases docetaxel cytotoxicity in the three cell lines and that docetaxel enhances NF- $\kappa \mathrm{B}$ activation $(31,39)$. However, when PC 3 cells are rendered docetaxel resistant, inhibition of $\mathrm{NF}-\kappa \mathrm{B}$ activity before docetaxel treatment, increases docetaxel cytotoxicity (31).

Cytokines and chemokines. Among the targets of $\mathrm{NF}-\kappa \mathrm{B}$ are the genes that encode IL- 6 and IL-8. These cytokines stimulate prostate cancer cell growth in an autocrine and paracrine manner and are involved in the development and progression of prostate cancer (40-43). PC3 and DU145 cells, instead of LNCaP cells, show elevated IL-6 and IL-8 production in conditioned media due to constitutive $\mathrm{NF}-\kappa \mathrm{B}$ activity $(40,42)$. Elevated IL-6 expression in CRPC cells activates the JAK-STAT pathway. IL-6 and IL-8 productions enhance proliferation and inhibit apoptosis in PC3 and DU145 cells (42). By these pathways, IL- 6 and IL- 8 are effectors of NF- $\kappa$ B in the resistance of CRPC cells to docetaxel $(39,42)$.

Another inflammatory molecule, the chemokine (C-C motif) ligand 2 (CCL2), is involved in the resistance of CRPC cells to docetaxel. CCL2 is expressed in prostate primary tumors (44) and correlated with their malignant potential (45). CCL2 is also expressed in prostate cancer cell lines (44), its expression is increased in CRPC cells by docetaxel (46). The binding of docetaxel to $\beta$-tubulin is sensed by microtubule interacting proteins which leads to activation of JNK signaling. Docetaxel via the JNK pathways upregulates CCL2 expression in CRPC cells (46). CCL2 acts in an autocrine manner to stimulate the Erk/MAP kinase and PI3K/AKT signaling pathways to promote tumor cell survival and resistance to docetaxel $(47,48)$.

Transforming growth factor- $\beta 1$ (TGF- $\beta 1$ ) is upregulated by the transcriptional factors Twist1 and YB-1, and participate to the docetaxel resistance of CRPC cells, as demonstrated in PC3 cells (49). By whole genome arrays, it was shown that TGF- $\beta$ receptor III (TGFBR3) is upregulated in both PC3 and DU145 docetaxel-resistant cell lines and interestingly other TGF- $\beta$ members appear deregulated in the same network (TGFB2, TGF- $\beta$ and LTBP2 for latent TGF- $\beta$ binding protein 2) (50).

The macrophage inhibitory cytokine-1 (MIC-1, also named growth differenciation factor 15 GDF15) is a member of TGF- $\beta$ superfamily expressed in numerous cells including epithelial cells and prostate cancer cells but its expression is higher in cancer cells and increased with cancer progression, particularly in prostate tumors and CRPC cells (51). Transcription of MIC-1 is suppressed by Egr-1 and p53, and activated by castration (52), hypoxia (53), HIF-1 $\alpha$ and NF- $\kappa \mathrm{B}$ (reviewed in ref. 54). MIC-1 overexpression in CRPC cells or their exposure to recombinant MIC-1 enhance their resistance to docetaxel (55). MIC-1 is upregulated in PC3 cells made resistant to docetaxel and its downregulation by siRNA sensitizes to docetaxel (56). Enhanced level of secreted MIC-1 in PC3 cells is associated with their acquisition of epithelialmesenchymal transition phenotype and docetaxel resistance, the downregulation of MIC-1 improves the efficacy of docetaxel cytotoxicity even in prostate cancer stem/progenitor cells (57). Therefore, docetaxel resistance and MIC-1 expression are directly linked in the total prostate cancer cell mass.
Chaperone molecules. Chaperone proteins are key components of alternative growth factor pathways upregulated in CRPC and are involved in docetaxel resistance pathways.

Heat shock proteins, notably HSP27 and HSP90 are overexpressed in CRPC cells and strategies to inhibit their expression restore docetaxel sensitivity. Nevertheless, clinical trials with HSP90 inhibitors have to date not succeed in improving overall survival, but trials with HSP27, second generation antisense drug (OGX-427) have shown a decrease in circulating tumor cells (CTC) in mCRPC patients, validating this chaperone therapeutic target. An ongoing study is now conducted with co-treatment of CRPC patients with docetaxel and OGX-427 (58). Clinical studies in CRPC patients targeting these chaperone molecules HSP90 and HSP27 and the chaperone clusterin are reported in Table I.

CLU is a key protein in the resistance to cancer chemotherapy, especially in the resistance of prostate cancer to docetaxel. CLU exists in two forms: a truncated nuclear form (nCLU) and a secreted form (sCLU). nCLU promotes CRPC cell death, however, nCLU is not detected in prostate tumor cells $(59,60)$ and in contrast sCLU prevents cell death. nCLU and sCLU are not produced at the same time, there is a shift from nCLU to sCLU production or vice versa (61), (reviewed in ref. 62). The level of overexpression of sCLU in docetaxel PC3-resistant cells is correlated to their level of docetaxel resistance (25). sCLU knockdown using antisense oligonucleotide increases the sensitivity of resistant PC3 cells in vitro (63) and in vivo (64). sCLU expression is induced by docetaxel via STAT-1 in PC3 and DU145 cells, it is higher in cells made resistant to docetaxel than in parental cells and inhibiting sCLU expression restores the reactivity to docetaxel $(35,63)$. It has been shown that AKT inhibition, either by a pharmacologic agent or by overexpression of dominant-negative AKT, suppresses CLU expression in the docetaxel resistant CRPC cells and sensitizes them again to docetaxel (59). Furthermore, these experiments and the transfection of constitutive active AKT that induces STAT-1 activation, show that CLU expression is dependent of AKT. CLU exerts its anti-apoptotic effect by binding unfolded proteins to prevent stress-induced protein aggregation. Notably, its binding and stabilization of the $\mathrm{Ku} 70$-Bax complex is a key factor preventing mitochondriamediated apoptosis (60). Such CLU binding prevents the release of Bax to the mitochondria to initiate cytochrome $c$ release and the resultant caspase-3-dependent apoptotic pathway.

CLU is regulated by TGF- $\beta 1$, via YB1 and contribute to the epithelial-mesenchymal transition and metastasis of prostate cancer cells (65). Moreover, the early growth response-1 (Erg-1) regulates sCLU expression. An inverse relationship between DOC-2/DAB2 interactive protein (DAP2IP) and Erg-1 or sCLU shown in DAB2IP ${ }^{-/-}$mouse and in CRPC patients, demonstrated that sCLU mediates the docetaxel resistance of DAP2IP deficient prostate cancer cells, since DAP2IP suppresses CLU expression by inhibiting Egr-1 gene transcription (66). Thus, clusterin is a key target to monitor and overcome docetaxel resistance in CRPC patients and a second generation antisense drug, OGX-011 also named custirsen, inhibiting the secretion of clusterin is now tested in 3 phase III clinical trials in CRPC patients, associated with taxane chemotherapy, as reported in Table I. 


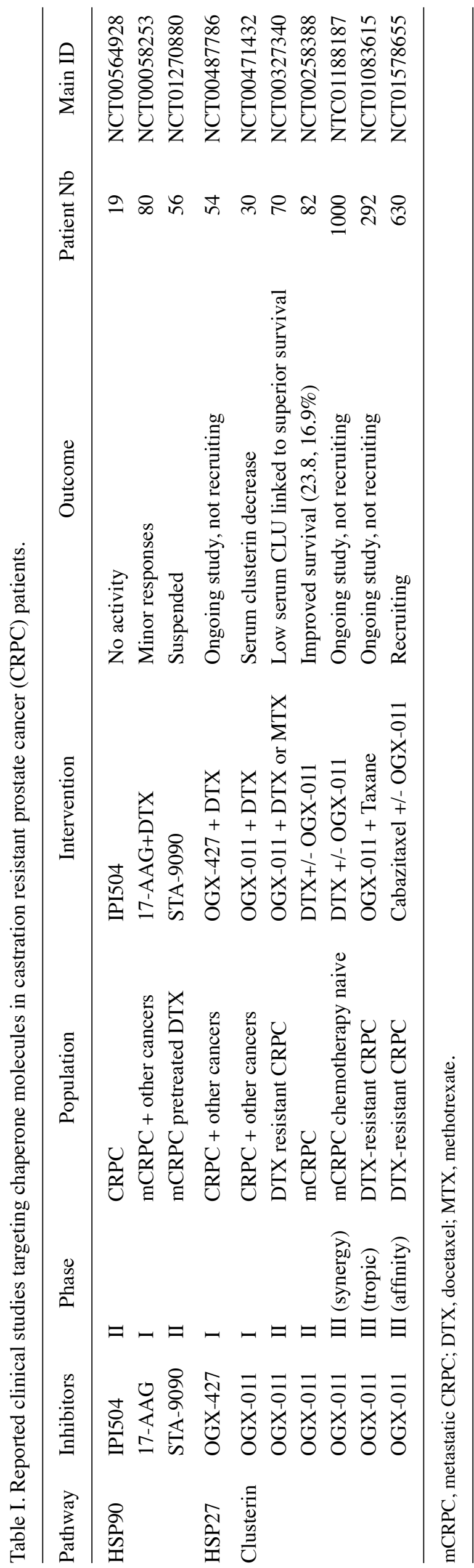

Microenvironment is involved in the resistance of CRPC to docetaxel. Docetaxel resistance is due to endogenous cell mechanisms but also to microenvironment. Microenvironment regulates the interstitial fluid pressure that is increased in many solid tumors (67). As a consequence, transvascular gradient is close to zero, because microvascular pressure is very close to the interstitial fluid pressure, reducing the fluid filtration in solid tumors. As a result, the delivery of drug including docetaxel in prostatic tissue is hindered (68).

Castration resistance is associated with increased angiogenesis in experimental models of prostate cancer and in patients (69-71). However, blood vessels of tumors, including prostate tumors, have multiple structural and functional abnormalities (72). Tumor vessels are more leaky than normal vessels, that enhances the fluid exchanges between the vascular and the interstitial space. Changes in the transvascular gradient induce a rapid fluid redistribution within the tumor tissue (73). Enhancement in fluid extravasation improves the delivery of drugs (68) including docetaxel in CRPC.

On the other hand, docetaxel reduces tumor angiogenesis (74). Docetaxel decreases the number of small diameter blood vessels in PC3 tumors induced in nude mice and acts also on endothelial cells in vitro by inhibiting endothelial cell proliferation and capillary development (75). Moreover, docetaxel inhibits endothelial cell migration in vitro and in vivo at low, not cytotoxic, doses (76). This is due to docetaxel inhibition of the VEGF receptor activity (77). Thus, VEGF and bFGF which are produced in PC3 and DU145 CRPC cells (78) and present in tumor microenvironment (79) are involved in tumor resistance to docetaxel. Consequently, during the course of the treatment, docetaxel itself restricts its access and impairs its delivery to tumor cells by reducing angiogenesis.

By increase of interstitial fluid pressure and decrease of angiogenesis, oxygen diffusion also is prevented making hypoxic areas in numerous solid tumors including prostate tumors (80). Hypoxic conditions elicit cellular responses designed to improve cell survival. The most important protein regulating the molecular response to hypoxia is the hypoxiainducible factor-1 (HIF-1). HIF-1 $\alpha$ expression activates the transcription of genes that are involved in angiogenesis, glucose metabolism, cell proliferation, apoptosis (decrease) and invasion (increase). All these responses would oppose docetaxel antitumor effect, thus, hypoxia is probably involved in docetaxel resistance. However, the few reports dealing with this subject show no modification of docetaxel cytotoxicity against CRPC cells between normoxia or hypoxia (81) or a decrease of apoptosis and an increase of necrosis under hypoxia, but no changes in the overall cytotoxicity (82).

Moreover, the tumor microenvironment is characterized by modified composition of extracellular matrix, infiltration of immune cells and release of numerous molecules as cytokines and chemokines. Stroma protects PC3 cells from docetaxel cytotoxicity: inhibition of CXCR4 or CXCL12 with antagonist or antibody, sensitized CRPC cells for docetaxel in vivo or in vitro in the presence of bone marrow derived stromal cells or of conditioned media from these cells (83). CXCR4 is the receptor of CXCL12, it is expressed at the surface of most of tumor cells $(84,85)$ and is an independent prognostic factor for poor overall survival in prostate cancer (86). Prostate cancer cells home to the bone marrow toward a CXCL12 


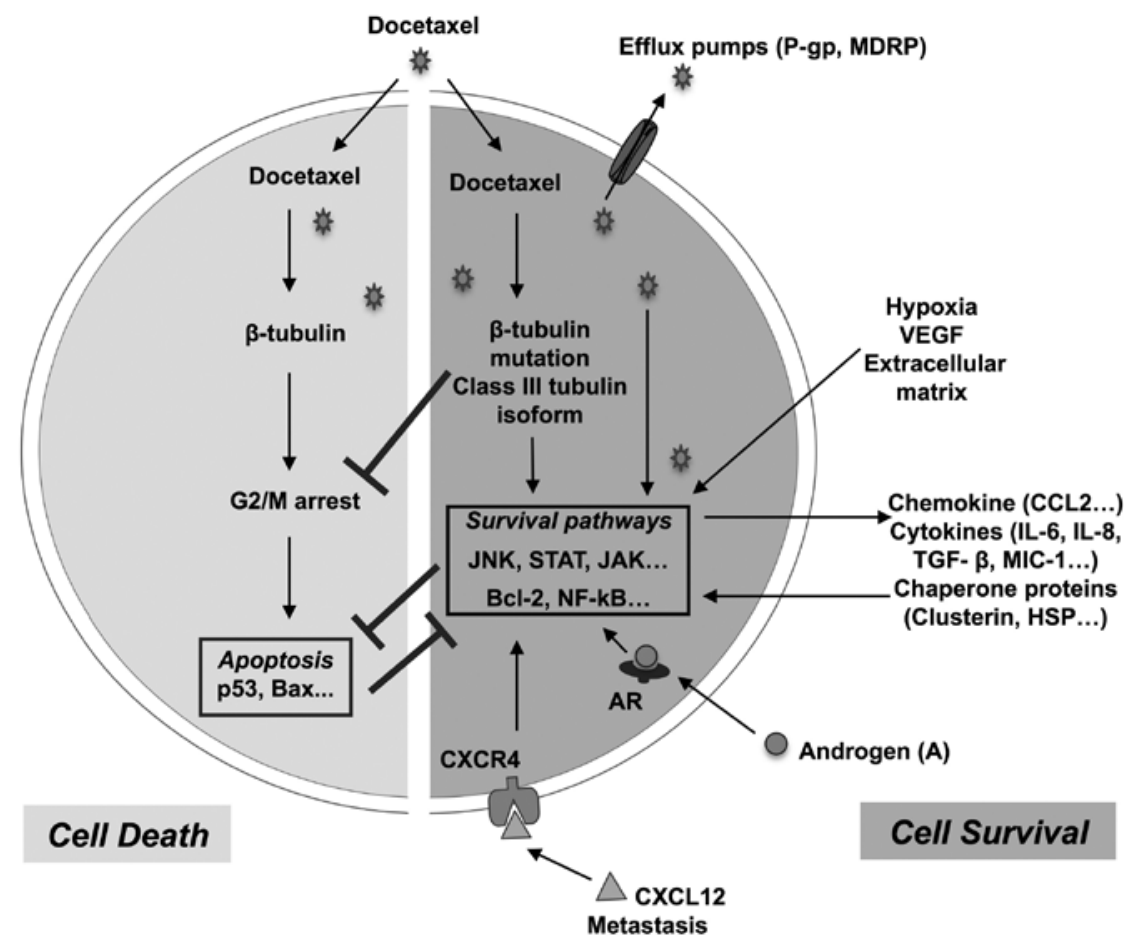

Figure 1. Docetaxel resistance pathways.

gradient $(87,88)$, CXCL12 binding to CXR4 protects CRPC cells to docetaxel cytotoxicity (83).

The various intrinsic and extrinsic docetaxel resistance mechanims are summerized in Fig. 1.

\section{Biological markers of docetaxel resistance}

Genomic and proteomic comparisons of CRPC cells or clinical samples from CRPC patients, treated or not with docetaxel, reveal various proteins that are expressed when the resistance is developing $(50,89)$. It is noteworthy that a protein of resistance is not necessarily a marker of resistance. There is an implication of the protein of resistance in the docetaxel resistance. While there is a correlation between the biological marker of resistance, its expression in the tumor or elsewhere (in the blood), and the resistance of tumor to docetaxel, that does not mean an involvement of the biological marker in the resistance. On the other hand, the correlation has to be evidenced in vitro and in clinical trials, to be shown as general and reproducible. Most, if not all, of the intracellular molecules that are candidate cannot be specified as biological markers, mainly because of the tumor heterogeneity that hinder this correlation and regardless to the difficulty to monitor an intracellular biological marker of resistance that would require tumor sampling during the treatment (90). Thus, we will focus this chapter on markers of resistance to docetaxel that are measured in the blood (serum) of patients and easily monitored during their treatment. There is consensus to accept some proteins as biological markers of resistance, i.e. prostate specific antigen, and the doubling time of its blood concentration, among the candidates are CLU, MIC-1 and IL-6. Other molecules, such as CCL2, are associated with the resistance of CRPC cells to docetaxel but are not acknowledged as biological markers in patients.
Prostate specific antigen (PSA). PSA is a serine protease which is routinely used as a biological detection and diagnostic marker for prostate cancer $(91,92)$. PSA concentration is associated with tumor volume and the velocity of its concentration doubling time in the blood of patients is well correlated to cytotoxic treatment effectiveness (93). This parameter is used to monitoring treatment efficacy, for the follow-up of prostate cancer patients and is as a classical outcome measure in prostate cancer clinical trials $(94,95)$. Therefore, in a patient, increase in PSA blood concentration is a biological marker of resistance to docetaxel of prostate tumors $(96,97)$.

PSA is, to date, the only relevant marker for prostate cancer, nevertheless, it has a low predictive value. Indeed, PSA does not discriminate between aggressive and non-aggressive prostate tumors (98) and in this way PSA is not a validated intermediate endpoint biomarker of survival in advanced prostate cancer (99). This highlights the importance for an effective prognostic and adapted therapeutic follow-up, to develop new blood biological markers for CRPC patients that would help to monitor the development of drug resistance.

Among other blood biological measures that are now evaluated as secondary outcomes in phase II or in observational clinical trials on CRPC patients under taxane treatment, by docetaxel alone or during the switch from docetaxel to cabazitaxel: i) some are based on cells such as the circulating tumor cell (CTC) enumeration, or the evaluation of the neutrophil lymphocyte ratio (NLR), ii) some are based on RNA analysis by targeted RT-PCR for gene expression profile evaluation, and iii) others are based on protein quantification such as neuroendocrine markers (chromogranin A, neuron specific enolase and progastrin-releasing peptide), bone markers (N-telopeptide of type I collagen and bone-specific alkaline phosphatase) to follow neuroendocrine and bone metastatic tumor cell populations, respectively, as well as already iden- 
Table II. Reported clinical studies recruiting CRPC patients and monitoring their taxane response by biomarker analysis on blood samples.

\begin{tabular}{|c|c|c|c|c|c|c|}
\hline Main ID & Study type & Treatment & Blood analysis & Outcome & Year & Patient no. \\
\hline NCT01160705 & Observational & DTX & $\begin{array}{l}\text { RNA analysis, RT-PCR, CTC, } \\
\text { biomarker analysis }\end{array}$ & Recruiting & 2010 & 50 \\
\hline ACTRN12611000540910 & Phase II & DTX & MIC-1 & Recruiting & 2011 & 150 \\
\hline NCT01718353 & Phase II & $\begin{array}{l}\text { DTX->Cabazitaxel } \\
\text { switch }\end{array}$ & CTC & Recruiting & 2012 & 100 \\
\hline DRKS00004797 & Observational & DTX or Cabazitaxel & $\begin{array}{l}\text { Neuroendocrine markers } \\
\text { CgA, NSE, ProGRP }\end{array}$ & Recruiting & 2013 & 75 \\
\hline
\end{tabular}

DTX, docetaxel; CTC, circulating tumor cell; CgA, chromogenin A; NSE, neuron specific enolase; Pro-GRP, pro-gastrin-releasing peptide.

tified docetaxel resistance markers the chaperone clusterin, the cytokines MIC-1 or IL-6. Examples of reported clinical studies recruiting CRPC patients and monitoring their taxane response by different blood biological measures is presented in Table II.

Clusterin. The involvement of sCLU in docetaxel resistance is now generally agreed, numerous data show that CLU is a protein of resistance to docetaxel. sCLU expression is higher in prostate tumors from patients treated with docetaxel than from control patients (63). Inhibiting clusterin expression in CRPC cells and CRPC patients prevents docetaxel resistance (see last paragraph). The transcription of sCLU is under the control of AP-1 (Jun and Fos), B-MYB, c-MYC, Egr-1, NF- $\mathrm{kB}$, HIF-1 $\alpha$, STAT-1 and p53, some of them can be constitutively active in prostate cancer cells (100). Moreover, some of these transcription factors are stimulated by constitutively activated signaling pathways, by microenvironment (hypoxia), and the expression of CLU can be induced in prostate cancer cells by castration. As a consequence, most CRPC cells express and produce sCLU and this expression can be enhanced by docetaxel. sCLU is secreted out of CRPC cells and binds to a scavenger receptor (megalin) at the surface or prostate cancer cells, the binding activates the PI3K/AKT pathway that induces sCLU production. Thus, sCLU constitutive expressed is increased by docetaxel and may be able to auto-regulate its own overexpression preventing prostate cancer apoptosis.

Only changes of concentration of the fully processed sCLU identified in the medium of CRPC cells is associated with the degree of cell line resistance to docetaxel (101). sCLU shows the characteristics of biomarker of docetaxel resistance in CRPC. Its evolution is closely linked with the resistance of CRPC cells to docetaxel. It is easily measured in the blood of patients and can be used to monitor the docetaxel effect. Biochemical recurrence-free survival in patients with elevated clusterin density was significantly shorter than in patients with normal density $(101,102)$. CLU is also a protein of resistance to cytotoxic cytokines TRAIL, TNF- $\alpha$, in CRPC cells $(103,104)$ and a resistance protein to a variety of drugs in different tumor types: such as taxol in human mammary cancer cells (105) or in human ovarian cancer cells (106) or gemcitabine in pancreatic cancer cells (107). Therefore, sCLU is a protein of resistance that could be useful as a therapeutic predictive biological marker in various cancers. If the sCLU blood concentration could be used to monitoring and predict docetaxel effectiveness in CRPC patients, inhibition of the expression of this resistance marker provide also an therapeutic approach to overcome docetaxel resistance.

Macrophage inhibitory cytokine 1 (MIC-1). MIC-1 inhibits tumor growth and induces apoptosis in the early stages of cancer, while it promotes the proliferation, migration and metastases formation in advanced stages of disease (108), thereby increasing the tumor cell resistance to docetaxel (reviewed in ref. 54). MIC-1 concentration in culture media is higher in docetaxel resistant PC3 cells than with parental cells (55), and is increased in the presence of docetaxel (56). Moreover, enhancement of the concentration of MIC-1 in blood from CRPC patients after the first cycle of docetaxel is significantly associated with cancer progression and shorter survival (56). This enhancement is due to tumor cell secretion since after docetaxel treatment MIC-1 expression is increased in tumor cells of prostate cancer tissue (55).

Furthermore, blood concentration of MIC-1 is an independent marker of high grade prostate cancer (109) and elevated blood MIC-1 concentration correlates with bone metastases (110). Also in colon cancer, serum MIC-1 level rises with increasing adenoma numbers and high-risk recurrence (111). Thus, MIC-1 could be a predictive biological marker for docetaxel effectiveness in CRPC patients. MIC-1 could predict, after the first cycle of docetaxel, the early resistance in CRPC patients and allow a decision: to continue or to stop the treatment. The evolution of this blood marker concentration will be followed in a clinical trial recruting 150 CRPC patients on docetaxel treatment (Table II).

Interleukin $6(I L-6)$. In CRPC patients treated with docetaxel, elevated baseline of IL- 6 concentration in serum is inversely correlated with time to progression and overall survival. Median overall survival was 6.8 months in patients with high IL-6 (>14 ng/ml) vs. 16.6 months in those with low IL-6 $(\leq 14 \mathrm{ng} / \mathrm{ml}$ ) (39). IL-6 appears to be involved in docetaxel resistance, however, conflicting data exist in the litterature (112). Recently, pre-treatment IL-6 level was identified as 
independent prognostic factor for overall survival in CRPC patients treated with docetaxel $(n=72)$, this pre-treatment IL-6 level correlating with nuclear $\mathrm{NF}-\kappa \mathrm{B} / \mathrm{p} 65$ tumor staining and response to docetaxel, but IL-6 level changes under treatment and did not correlate with clinical outcome (113). As for clusterin, strategy to inhibit IL-6 synthesis and to overcome docetaxel resistance are under evaluation. Serum $C$ reactive protein (CRP) production by the liver may reflect the activity of inflammatory cytokines such as IL- 6 that can be produce by docetaxel-resistant prostate cancer cells. CRP functions adequately as a clinical marker, therefore, a modified Glasgow prognostic score (mGPS) has been proposed. CRP quantification is included as an independent prognostic factor for overall survival (114).

\section{New therapies intended to overcome docetaxel resistance of CRPC}

The aims of these therapies are either to bypass docetaxel resistance using other antitumoral pathways or to inhibit the docetaxel resistance mechanisms.

Among the other antitumoral approaches, immunotherapy is challenging. Sipuleucel-T in 2010 was the first antitumoral cellular vaccine approved by FDA. In patients with metastatic CRPC, this cell vaccine resulted in 4.1 months improvement in the median overall survival (25.8 months in the sipuleucel-T group vs. 21.7 months in the placebo group) (115). New generation of hormonotherapeutics have also been approved, as the androgen biosynthesis inhibitor abiraterone (CYP17 inhibitor) or the AR antagonist enzalutamide (MDV 3100). In addition is the radiopharmaceutical alpharadin (radium-223 chloride).

The number of new therapies intended to overcome docetaxel resistance development in CRPC are far less numerous.

The therapies are based on different mechanisms. For example, new drugs have been developed, that keep the same molecular target but with limiting drug efflux. This is the case of cabazitaxel, a second-generation taxane that has low affinity for MDR proteins, unlike docetaxel, which is a known P-gp substrate. Cabazitaxel, was recently reported to have an OS benefit in patients with prostate cancer who have progressed on docetaxel (116) and is now approved by FDA.

Moreover, an inhibitor of the $\mathrm{NF}-\kappa \mathrm{B}$ survival pathway implied in the endogenous docetaxel cell resistance pathway have also been approved for the treatment of CRPC. This is the case of denosumab an antibody against the receptor activator of nuclear factor $\kappa \mathrm{B}$ ligand (RANK-L).

Thus, among the treatments which have been approved by FDA for docetaxel resistant CRPC patients, only cabazitaxel and denosumab can be attributed more or less directly to interfere with the pathways of endogenous docetaxel cell resistance (117).

New therapies for CRPC resistant to docetaxel are currently tested in phase II and III trials, and many new ones are currently on the horizon.

Target therapy to stimulate apoptosis or inhibit survival pathways with monoclonal antibodies or small inhibitors (as IKK inhibitors PS1145, BAY 11-7082) are under evaluation. Concerning the targeting of chaperone molecules, this is the case of custirsen that prevents the production of CLU induced by docetaxel. CLU knockdown using antisense oligonucleotides or siRNA, decreases sCLU expression in CRPC cells and reduces their resistance to docetaxel in vitro and in vivo in nude mice (63). A phase II trial using a CLU inhibitor (custirsen OGX-011 an antisense inhibitor of CLU) in association with docetaxel is ongoing. Serum CLU concentration was negatively correlated with survival, better PSA response rates is seen in the docetaxel arm (40 vs. 27\%) and overall survival confirms this (14.7 vs. 11.4 months) (118). Three phase III studies looking at the activity of custirsen both in combination with taxanes (docetaxel or cabazitaxel) and after docetaxel are currently underway (Table I).

Cytokines are also potential targets to overcome docetaxel resistance. A phase I study of a chimeric antibody against IL-6 (Siltuximab) given combined with docetaxel demonstrates the safety of this approach and shows preliminary efficacy in patients with metastatic CRPC (119). As expected, CRP concentration were suppressed during this treatment.

Moreover, targeting the tumor microenvironment is also challenging to control docetaxel resistance development. Inhibition of angiogenesis theoretically would not overcome docetaxel resistance since docetaxel itself reduces CRPC angiogenesis. However, inhibition of VEGF activity is more than the inhibition of angiogenesis, it is to inhibit VEGF signaling. Combination of bevacizumab, anti-VEGF antibody, with docetaxel in CRPC docetaxel resistant patients in phase II trial showed interesting findings. Major PSA responses were observed in previous responders to docetaxel alone, evidencing that bevacizumab could return activity to docetaxel (120). However, a phase III study with docetaxel plus prednisone with or without bevacizumab failed to obtain OS advantage and serious morbidity and mortality rates were seen (121). Another combination of docetaxel in first line and VEGFtrap (aflibercept) under investigation in phase III with CRPC patients has completed accrual and results are awaited (122).

Other clinical trials are currently investigating the combination of tyrosine kinase inhibitors or anti-apoptotic protein inhibitors with docetaxel in CRPC (reviewed in ref. 123) but, with anti-VEGF, they are not truly inhibitors of resistance mechanisms induced by docetaxel, but inhibitors of general mechanisms induced by oncogenesis. Intermittent therapy to avoid docetaxel resistance has not be sucessful (124). Since many therapeutic options are under evaluation to overome docetaxel resistance, more investigations should be performed on the optimal combination or the sequence of treatments needed in order to maximize the clinical benefits for the patients.

\section{Conclusion}

There is no standard second line treatment for CRPC patients resistant to docetaxel. Since 2010 Food and Drug Administration (FDA) and European Medicines Agency (EMA) have approved six new molecules: cabazitaxel, abiraterone, enzalutamide, Sipuleucel T, denosumab and Alpharadin. Cabazitaxel is a second-generation taxane, abiratrone is an inhibitor of cytochrome $\mathrm{P} 450$ that inhibits de novo biosynthesis of androgens, enzalutamide is an androgen receptor antagonist, Sipuleucel T is an immunotherapy, denosumab is an antibody against RANK ligand and Alpharadin is 
a radiopharmaceutical. Most of these new molecules are not intended to directly overcome docetaxel resistance. Although to bypass docetaxel resistance using molecules that go by other pathways is intellectually, a priori, more satisfactory, to inhibit the mechanisms of docetaxel resistance could be perhaps more secure. We know that docetaxel is effective, it would be perhaps easier and more profitable to overcome its mechanisms of resistance than to find new effective pathways. Indeed, as we report in the present review many data support the investigation of targeted therapies to enhance the antitumor activity of docetaxel, and custirsen may give the answer.

\section{References}

1. Feldman BJ and Feldman D: The development of androgenindependent prostate cancer. Nat Rev Cancer 1: 34-45, 2001.

2. Yap TA, Zivi A, Omlin A and de Bono JS: The changing therapeutic landscape of castration-resistant prostate cancer. Nat Rev Clin Oncol 8: 597-610, 2011.

3. Eisenberger MA and Walsh PC: Early androgen deprivation for prostate cancer? N Engl J Med 341: 1837-1838, 1999.

4. Visakorpi T, Hyytinen E, Koivisto P, et al: In vivo amplification of the androgen receptor gene and progression of human prostate cancer. Nat Genet 9: 401-406, 1995.

5. Taplin ME, Bubley GJ, Shuster TD, et al: Mutation of the androgen-receptor gene in metastatic androgen-independent prostate cancer. N Engl J Med 332: 1393-1398, 1995.

6. Taplin ME, Bubley GJ, Ko YJ, et al: Selection for androgen receptor mutations in prostate cancers treated with androgen antagonist. Cancer Res 59: 2511-2515, 1999.

7. Yamaoka M, Hara T and Kusaka M: Overcoming persistent dependency on androgen signaling after progression to castration-resistant prostate cancer. Clin Cancer Res 16: 4319-4324, 2010.

8. Araki S, Omori Y, Lyn D, et al: Interleukin-8 is a molecular determinant of androgen independence and progression in prostate cancer. Cancer Res 67: 6854-6862, 2007.

9. Xu Y, Josson S, Fang F, et al: RelB enhances prostate cancer growth: implications for the role of the nuclear factor- $\kappa \mathrm{B}$ alternative pathway in tumorigenicity. Cancer Res 69: 3267-3271, 2009.

10. Tannock IF, de Wit R, Berry WR, et al: Docetaxel plus prednisone or mitoxantrone plus prednisone for advanced prostate cancer. N Engl J Med 351: 1502-1512, 2004.

11. Serpa Neto A, Tobias-Machado M, Kaliks R, Wroclawski ML, Pompeo AC and Del Giglio A: Ten years of docetaxel-based therapies in prostate adenocarcinoma: a systematic review and meta-analysis of 2244 patients in 12 randomized clinical trials. Clin Genitourin Cancer 9: 115-123, 2011.

12. Marech I, Vacca A, Ranieri G, Gnoni A and Dammacco F: Novel strategies in the treatment of castration-resistant prostate cancer (Review). Int J Oncol 40: 1313-1320, 2012.

13. Seruga B and Tannock IF: Chemotherapy-based treatment for castration-resistant prostate cancer. J Clin Oncol 29: 3686-3694, 2011.

14. El-Amm J and Aragon-Ching JB: The changing landscape in the treatment of metastatic castration-resistant prostate cancer. Ther Adv Med Oncol 5: 25-40, 2013.

15. Shelanski ML, Gaskin F and Cantor CR: Microtubule assembly in the absence of added nucleotides. Proc Natl Acad Sci USA 70: 765-768, 1973

16. McGrogan BT, Gilmartin B, Carney DN and McCann A: Taxanes, microtubules and chemoresistant breast cancer. Biochim Biophys Acta 1785: 96-132, 2008.

17. Zhu J, Beattie EC, Yang Y, Wang HJ, Seo JY and Yang LX: Centrosome impairments and consequent cytokinesis defects are possible mechanisms of taxane drugs. Anticancer Res 25: 1919-1925, 2005.

18. Fabbri F, Amadori D, Carloni S, et al: Mitotic catastrophe and apoptosis induced by docetaxel in hormone-refractory prostate cancer cells. J Cell Physiol 217: 494-501, 2008.

19. Kramer G, Schwarz S, Hägg M, Havelka AM and Linder S: Docetaxel induces apoptosis in hormone refractory prostate carcinomas during multiple treatment cycles. Br J Cancer 94 1592-1598, 2006.
20. Mediavilla-Varela M, Pacheco FJ, Almaguel F, et al: Docetaxelinduced prostate cancer cell death involves concomitant activation of caspase and lysosomal pathways and is attenuated by LEDGF/p75. Mol Cancer 8: 68, 2009.

21. Kim JY, Chung JY, Lee SG, et al: Nuclear interaction of Smac/ DIABLO with Survivin at G2/M arrest prompts docetaxelinduced apoptosis in DU145 prostate cancer cells. Biochem Biophys Res Commun 350: 949-954, 2006.

22. Kuroda K, Liu H, Kim S, Guo M, Navarro V and Bander NH: Docetaxel down-regulates the expression of androgen receptor and prostate-specific antigen but not prostate-specific membrane antigen in prostate cancer cell lines: implications for PSA surrogacy. Prostate 69: 1579-1585, 2009.

23. Seruga B, Ocana A and Tannock IF: Drug resistance in metastatic castration-resistant prostate cancer. Nat Rev Clin Oncol 8: 12-23, 2011.

24. Sissung TM, Baum CE, Deeken J, et al: $A B C B 1$ genetic variation influences the toxicity and clinical outcome of patients with androgen-independent prostate cancer treated with docetaxel. Clin Cancer Res 14: 4543-4549, 2008

25. O'Neill AJ, Prencipe M, Dowling C, et al: Characterisation and manipulation of docetaxel resistant prostate cancer cell lines. Mol Cancer 10: 126, 2011.

26. Xie Y, Xu K, Linn DE, et al: The 44-kDa Pim-1 kinase phosphorylates BCRP/ABCG2 and thereby promotes its multimerization and drug-resistant activity in human prostate cancer cells. J Biol Chem 283: 3349-3356, 2008.

27. Terry S, Ploussard G, Allory Y, et al: Increased expression of class III $\beta$-tubulin in castration-resistant human prostate cancer. Br J Cancer 101: 951-956, 2009.

28. Ploussard G, Terry S, Maille P, et al: Class III $\beta$-tubulin expression predicts prostate tumor aggressiveness and patient response to docetaxel-based chemotherapy. Cancer Res 70: 9253-9264, 2010.

29. Hara T, Ushio K, Nishiwaki M, et al: A mutation in $\beta$-tubulin and a sustained dependence on androgen receptor signalling in a newly established docetaxel-resistant prostate cancer cell line. Cell Biol Int 34: 177-184, 2010.

30. Heidenberg HB, Bauer JJ, McLeod DG, Moul JW and Srivastava S: The role of the p53 tumor suppressor gene in prostate cancer: a possible biomarker? Urology 48: 971-979, 1996.

31. Gan L, Wang J, Xu H and Yang X: Resistance to docetaxelinduced apoptosis in prostate cancer cells by p38/p53/p21 signaling. Prostate 71: 1158-1166, 2011.

32. Yoshino T, Shiina H, Urakami S, et al: Bcl-2 expression as a predictive marker of hormone-refractory prostate cancer treated with taxane-based chemotherapy. Clin Cancer Res 12: 6116-6124, 2006.

33. Lebedeva I, Rando R, Ojwang J, Cossum P and Stein CA: Bcl-xL in prostate cancer cells: effects of overexpression and downregulation on chemosensitivity. Cancer Res 60: 6052-6060, 2000.

34. Tantivejkul K, Loberg RD, Mawocha SC, et al: PAR1-mediated $\mathrm{NF}-\kappa \mathrm{B}$ activation promotes survival of prostate cancer cells through a Bcl-xL-dependent mechanism. J Cell Biochem 96: 641-652, 2005.

35. Patterson SG, Wei S, Chen X, et al: Novel role of Stat1 in the development of docetaxel resistance in prostate tumor cells. Oncogene 25: 6113-6122, 2006.

36. Zemskova M, Sahakian E, Bashkirova S and Lilly M: The PIM1 kinase is a critical component of a survival pathway activated by docetaxel and promotes survival of docetaxel-treated prostate cancer cells. J Biol Chem 283: 20635-20644, 2008.

37. Shimada K, Nakamura M, Ishida E, Kishi M, Yonehara S and Konishi N: Contributions of mitogen-activated protein kinase and nuclear factor kappa B to $N$-(4-hydroxyphenyl)retinamideinduced apoptosis in prostate cancer cells. Mol Carcinog 35: 127-137, 2002.

38. Palayoor ST, Youmell MY, Calderwood SK, Coleman CN and

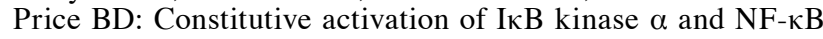
in prostate cancer cells is inhibited by ibuprofen. Oncogene 18: 7389-7394, 1999.

39. Domingo-Domenech J, Oliva C, Rovira A, et al: Interleukin 6, a nuclear factor- $\kappa \mathrm{B}$ target, predicts resistance to docetaxel in hormone-independent prostate cancer and nuclear factor- $\kappa \mathrm{B}$ inhibition by PS-1145 enhances docetaxel antitumor activity. Clin Cancer Res 12: 5578-5586, 2006.

40. Zerbini LF, Wang Y, Cho JY and Libermann TA: Constitutive activation of nuclear factor $\kappa \mathrm{B}$ p50/p65 and Fra- 1 and JunD is essential for deregulated interleukin 6 expression in prostate cancer. Cancer Res 63: 2206-2215, 2003. 
41. Michalaki V, Syrigos K, Charles P and Waxman J: Serum levels of IL-6 and TNF- $\alpha$ correlate with clinicopathological features and patient survival in patients with prostate cancer. $\mathrm{Br} \mathrm{J}$ Cancer 90: 2312-2316, 2004.

42. Singh RK and Lokeshwar BL: Depletion of intrinsic expression of Interleukin-8 in prostate cancer cells causes cell cycle arrest, spontaneous apoptosis and increases the efficacy of chemotherapeutic drugs. Mol Cancer 8: 57, 2009.

43. Inoue K, Slaton JW, Eve BY, et al: Interleukin 8 expression regulates tumorigenicity and metastases in androgen-independent prostate cancer. Clin Cancer Res 6: 2104-2119, 2000.

44. Lu Y, Cai Z, Galson DL, et al: Monocyte chemotactic protein-1 (MCP-1) acts as a paracrine and autocrine factor for prostate cancer growth and invasion. Prostate 66: 1311-1318, 2006.

45. Shirotake S, Miyajima A, Kosaka T, et al: Regulation of monocyte chemoattractant protein-1 through angiotensin II type 1 receptor in prostate cancer. Am J Pathol 180: 1008-1016, 2012.

46. Qian DZ, Rademacher BL, Pittsenbarger J, et al: CCL2 is induced by chemotherapy and protects prostate cancer cells from docetaxel-induced cytotoxicity. Prostate 70: 433-442, 2010.

47. Roca H, Varsos ZS and Pienta KJ: CCL2 is a negative regulator of AMP-activated protein kinase to sustain mTOR complex-1 activation, survivin expression, and cell survival in human prostate cancer PC3 cells. Neoplasia 11: 1309-1317, 2009.

48. Loberg RD, Day LL, Harwood J, et al: CCL2 is a potent regulator of prostate cancer cell migration and proliferation. Neoplasia 8 . 578-586, 2006

49. Shiota M, Kashiwagi E, Yokomizo A, et al: Interaction between docetaxel resistance and castration resistance in prostate cancer: implications of Twist1, YB-1, and androgen receptor. Prostate 73: 1336-1344, 2013.

50. Marin-Aguilera M, Codony-Servat J, Kalko SG, et al: Identification of docetaxel resistance genes in castration-resistant prostate cancer. Mol Cancer Ther 11: 329-339, 2012.

51. Patrikainen L, Porvari K, Kurkela R, Hirvikoski P, Soini Y and Vihko P: Expression profiling of PC3 cell line variants and comparison of MIC-1 transcript levels in benign and malignant prostate. Eur J Clin Invest 37: 126-133, 2007.

52. Karan D, Kelly DL, Rizzino A, Lin MF and Batra SK: Expression profile of differentially-regulated genes during progression of androgen-independent growth in human prostate cancer cells. Carcinogenesis 23: 967-975, 2002.

53. Kelly JA, Lucia MS and Lambert JR: p53 controls prostatederived factor/macrophage inhibitory cytokine/NSAID-activated gene expression in response to cell density, DNA damage and hypoxia through diverse mechanisms. Cancer Lett 277: 38-47, 2009.

54. Mimeault M and Batra SK: Divergent molecular mechanisms underlying the pleiotropic functions of macrophage inhibitory cytokine-1 in cancer. J Cell Physiol 224: 626-635, 2010.

55. Huang CY, Beer TM, Higano CS, et al: Molecular alterations in prostate carcinomas that associate with in vivo exposure to chemotherapy: identification of a cytoprotective mechanism involving growth differentiation factor 15. Clin Cancer Res 13: 5825-5833, 2007.

56. Zhao L, Lee BY, Brown DA, et al: Identification of candidate biomarkers of therapeutic response to docetaxel by proteomic profiling. Cancer Res 69: 7696-7703, 2009.

57. Mimeault M, Johansson SL and Batra SK: Marked improvement of cytotoxic effects induced by docetaxel on highly metastatic and androgen-independent prostate cancer cells by downregulating macrophage inhibitory cytokine-1. Br J Cancer 108: 1079-1091, 2013.

58. Shiota M, Bishop JL, Nip KM, et al: Hsp27 regulates epithelial mesenchymal transition, metastasis, and circulating tumor cells in prostate cancer. Cancer Res 73: 3109-3119, 2013.

59. Zhong B, Sallman DA, Gilvary DL, et al: Induction of clusterin by AKT - role in cytoprotection against docetaxel in prostate tumor cells. Mol Cancer Ther 9: 1831-1841, 2010.

60. Zhang H,Kim JK, Edwards CA, Xu Z, Taichman R and Wang CY: Clusterin inhibits apoptosis by interacting with activated Bax. Nat Cell Biol 7: 909-915, 2005.

61. Pucci S, Bonanno E, Pichiorri F, Angeloni C and Spagnoli LG: Modulation of different clusterin isoforms in human colon tumorigenesis. Oncogene 23: 2298-2304, 2004.

62. Shannan B, Seifert M, Leskov K, et al: Challenge and promise: roles for clusterin in pathogenesis, progression and therapy of cancer. Cell Death Differ 13: 12-19, 2006.
63. Sowery RD, Hadaschik BA, So AI, et al: Clusterin knockdown using the antisense oligonucleotide OGX-011 re-sensitizes docetaxel-refractory prostate cancer PC 3 cells to chemotherapy. BJU Int 102: 389-397, 2008.

64. Springate CM, Jackson JK, Gleave ME and Burt HM: Efficacy of an intratumoral controlled release formulation of clusterin antisense oligonucleotide complexed with chitosan containing paclitaxel or docetaxel in prostate cancer xenograft models. Cancer Chemother Pharmacol 56: 239-247, 2005.

65. Shiota M,Zardan A, Takeuchi A, et al: Clusterin mediates TGF- $\beta$ induced epithelial-mesenchymal transition and metastasis via Twist1 in prostate cancer cells. Cancer Res 72: 5261-5272, 2012.

66. Wu K, Xie D, Zou Y, et al: The mechanism of DAB2IP in chemoresistance of prostate cancer cells. Clin Cancer Res 19: 4740-4749, 2013.

67. Heldin $\mathrm{CH}$, Rubin K, Pietras K and Ostman A: High interstitial fluid pressure - an obstacle in cancer therapy. Nat Rev Cancer 4: 806-813, 2004.

68. Netti PA, Hamberg LM, Babich JW, et al: Enhancement of fluid filtration across tumor vessels: implication for delivery of macromolecules. Proc Natl Acad Sci USA 96: 3137-3142, 1999.

69. Tomic TT, Gustavsson H, Wang W, Jennbacken K, Welen K and Damber JE: Castration resistant prostate cancer is associated with increased blood vessel stabilization and elevated levels of VEGF and Ang-2. Prostate 72: 705-712, 2012.

70. Gustavsson H, Welen K and Damber JE: Transition of an androgen-dependent human prostate cancer cell line into an androgen-independent subline is associated with increased angiogenesis. Prostate 62: 364-373, 2005.

71. Gustavsson H, Wang W, Jennbacken K, Welen K and Damber JE: ADAMTS1, a putative anti-angiogenic factor, is decreased in human prostate cancer. BJU Int 104: 1786-1790, 2009.

72. Eberhard A, Kahlert S, Goede V, Hemmerlein B, Plate KH and Augustin HG: Heterogeneity of angiogenesis and blood vessel maturation in human tumors: implications for antiangiogenic tumor therapies. Cancer Res 60: 1388-1393, 2000.

73. Netti PA, Baxter LT, Boucher Y, Skalak R and Jain RK: Timedependent behavior of interstitial fluid pressure in solid tumors: implications for drug delivery. Cancer Res 55: 5451-5458, 1995.

74. Wilson C, Scullin P, Worthington J, et al: Dexamethasone potentiates the antiangiogenic activity of docetaxel in castrationresistant prostate cancer. Br J Cancer 99: 2054-2064, 2008.

75. Sweeney CJ, Miller KD, Sissons SE, et al: The antiangiogenic property of docetaxel is synergistic with a recombinant humanized monoclonal antibody against vascular endothelial growth factor or 2-methoxyestradiol but antagonized by endothelial growth factors. Cancer Res 61: 3369-3372, 2001.

76. Hotchkiss KA, Ashton AW, Mahmood R, Russell RG, Sparano JA and Schwartz EL: Inhibition of endothelial cell function in vitro and angiogenesis in vivo by docetaxel (taxotere): association with impaired repositioning of the microtubule organizing center. Mol Cancer Ther 1: 1191-1200, 2002.

77. Murtagh J, Lu H and Schwartz EL: Taxotere-induced inhibition of human endothelial cell migration is a result of heat shock protein 90 degradation. Cancer Res 66: 8192-8199, 2006.

78. Erten C, Karaca B, Kucukzeybek Y, et al: Regulation of growth factors in hormone- and drug-resistant prostate cancer cells by synergistic combination of docetaxel and octreotide. BJU Int 104: 107-114, 2009.

79. Bok RA, Halabi S, Fei DT, et al: Vascular endothelial growth factor and basic fibroblast growth factor urine levels as predictors of outcome in hormone-refractory prostate cancer patients: a cancer and leukemia group B study. Cancer Res 61: 2533-2536, 2001.

80. Tatum JL, Kelloff GJ, Gillies RJ, et al: Hypoxia: importance in tumor biology, noninvasive measurement by imaging, and value of its measurement in the management of cancer therapy. Int $\mathrm{J}$ Radiat Biol 82: 699-757, 2006.

81. Forde JC, Perry AS, Brennan K, et al: Docetaxel maintains its cytotoxic activity under hypoxic conditions in prostate cancer cells. Urol Oncol 30: 912-919, 2012.

82. Thews O, Gassner B, Kelleher DK, Schwerdt G and Gekle M: Impact of hypoxic and acidic extracellular conditions on cytotoxicity of chemotherapeutic drugs. Adv Exp Med Biol 599: 155-161, 2007.

83. Domanska UM, Timmer-Bosscha H, Nagengast WB, et al: CXCR4 inhibition with AMD3100 sensitizes prostate cancer to docetaxel chemotherapy. Neoplasia 14: 709-718, 2012

84. Sun YX, Wang J, Shelburne CE, et al: Expression of CXCR4 and CXCL12 (SDF-1) in human prostate cancers (PCa) in vivo. J Cell Biochem 89: 462-473, 2003. 
85. Engl T, Relja B, Marian D, et al: CXCR4 chemokine receptor mediates prostate tumor cell adhesion through $\alpha_{5}$ and $\beta_{3}$ integrins. Neoplasia 8: 290-301, 2006.

86. Akashi T, Koizumi K, Tsuneyama K, Saiki I, Takano Y and Fuse H: Chemokine receptor CXCR4 expression and prognosis in patients with metastatic prostate cancer. Cancer Sci 99: 539-542, 2008.

87. Taichman RS, Cooper C, Keller ET, Pienta KJ, Taichman NS and McCauley LK: Use of the stromal cell-derived factor-1/ CXCR4 pathway in prostate cancer metastasis to bone. Cancer Res 62: 1832-1837, 2002

88. Shiozawa Y, Pedersen EA, Havens AM, et al: Human prostate cancer metastases target the hematopoietic stem cell niche to establish footholds in mouse bone marrow. J Clin Invest 121: 1298-1312, 2011.

89. Desarnaud F, Geck P,Parkin C, Carpinito G and Makarovskiy AN: Gene expression profiling of the androgen independent prostate cancer cells demonstrates complex mechanisms mediating resistance to docetaxel. Cancer Biol Ther 11: 204-212, 2011.

90. Bjartell A, Montironi R, Berney DM and Egevad L: Tumour markers in prostate cancer II: diagnostic and prognostic cellular biomarkers. Acta Oncol 50 (Suppl 1): 76-84, 2011.

91. Stamey TA, Yang N, Hay AR, McNeal JE, Freiha FS and Redwine E: Prostate-specific antigen as a serum marker for adenocarcinoma of the prostate. N Engl J Med 317: 909-916, 1987.

92. Catalona WJ, Smith DS, Ratliff TL, et al: Measurement of prostate-specific antigen in serum as a screening test for prostate cancer. N Engl J Med 324: 1156-1161, 1991.

93. Smith DC, Dunn RL, Strawderman MS and Pienta KJ: Change in serum prostate-specific antigen as a marker of response to cytotoxic therapy for hormone-refractory prostate cancer. J Clin Oncol 16: 1835-1843, 1998.

94. Petrylak DP, Ankerst DP, Jiang CS, et al: Evaluation of prostatespecific antigen declines for surrogacy in patients treated on SWOG 99-16. J Natl Cancer Inst 98: 516-521, 2006.

95. Colloca G: Prostate-specific antigen kinetics as a surrogate endpoint in clinical trials of metastatic castration-resistant prostate cancer: a review. Cancer Treat Rev 38: 1020-1026, 2012

96. Berry W and Eisenberger M: Achieving treatment goals for hormone-refractory prostate cancer with chemotherapy. Oncologist 10 (Suppl 3): 30-39, 2005.

97. Ross RW, Galsky MD, Febbo P, et al: Phase 2 study of neoadjuvant docetaxel plus bevacizumab in patients with high-risk localized prostate cancer: a Prostate Cancer Clinical Trials Consortium trial. Cancer 118: 4777-4784, 2012.

98. Sokoll LJ, Sanda MG, Feng Z, et al: A prospective, multicenter, National Cancer Institute Early Detection Research Network study of [-2]proPSA: improving prostate cancer detection and correlating with cancer aggressiveness. Cancer Epidemiol Biomarkers Prev 19: 1193-1200, 2010.

99. Yap TA, Swanton C and de Bono JS: Personalization of prostate cancer prevention and therapy: are clinically qualified biomarkers in the horizon? EPMA J 3: 3, 2012.

100. Sala A, Bettuzzi S, Pucci S, Chayka O, Dews $M$ and Thomas-Tikhonenko A: Regulation of CLU gene expression by oncogenes and epigenetic factors implications for tumorigenesis. Adv Cancer Res 105: 115-132, 2009.

101. Girard FP, Byrne J, Downes M, et al: Detecting soluble clusterin in in-vitro and in-vivo models of prostate cancer. Neoplasma 57: 488-493, 2010.

102. Miyake H, Muramaki M, Furukawa J, Kurahashi T and Fujisawa M: Serum level of clusterin and its density in men with prostate cancer as novel biomarkers reflecting disease extension. Urology 75: 454-459, 2010.

103. Sensibar JA, Sutkowski DM, Raffo A, et al: Prevention of cell death induced by tumor necrosis factor $\alpha$ in LNCaP cells by overexpression of sulfated glycoprotein-2 (clusterin). Cancer Res 55: 2431-2437, 1995.

104. Sallman DA, Chen X, Zhong B, et al: Clusterin mediates TRAIL resistance in prostate tumor cells. Mol Cancer Ther 6: 2938-2947, 2007.

105. So A, Sinnemann S, Huntsman D, Fazli L and Gleave M: Knockdown of the cytoprotective chaperone, clusterin, chemosensitizes human breast cancer cells both in vitro and in vivo. Mol Cancer Ther 4: 1837-1849, 2005.
106. Park DC, Yeo SG, Wilson MR, et al: Clusterin interacts with paclitaxel and confer paclitaxel resistance in ovarian cancer. Neoplasia 10: 964-972, 2008.

107. Tang Y, Liu F, Zheng C, Sun S and Jiang Y: Knockdown of clusterin sensitizes pancreatic cancer cells to gemcitabine chemotherapy by ERK1/2 inactivation. J Exp Clin Cancer Res 31: 73, 2012.

108. Breit SN, Johnen H, Cook AD, et al: The TGF- $\beta$ superfamily cytokine, MIC-1/GDF15: a pleotrophic cytokine with roles in inflammation, cancer and metabolism. Growth Factors 29: 187-195, 2011.

109. Brown DA, Stephan C, Ward RL, et al: Measurement of serum levels of macrophage inhibitory cytokine 1 combined with prostate-specific antigen improves prostate cancer diagnosis. Clin Cancer Res 12: 89-96, 2006

110. Selander KS, Brown DA, Sequeiros GB, et al: Serum macrophage inhibitory cytokine-1 concentrations correlate with the presence of prostate cancer bone metastases. Cancer Epidemiol Biomarkers Prev 16: 532-537, 2007.

111. Brown DA, Hance KW, Rogers CJ, et al: Serum macrophage inhibitory cytokine-1 (MIC-1/GDF15): a potential screening tool for the prevention of colon cancer? Cancer Epidemiol Biomarkers Prev 21: 337-346, 2012.

112. Ignatoski KM, Friedman J, Escara-Wilke J, et al: Change in markers of bone metabolism with chemotherapy for advanced prostate cancer: interleukin- 6 response is a potential early indicator of response to therapy. J Interferon Cytokine Res 29: $105-112,2009$

113. Codony-Servat J, Marin-Aguilera M, Visa L, et al: Nuclear factor-kappa B and interleukin-6 related docetaxel resistance in castration-resistant prostate cancer. Prostate 73: 512-521, 2013.

114. Ito M, Saito K, Yasuda Y, et al: Prognostic impact of C-reactive protein for determining overall survival of patients with castration-resistant prostate cancer treated with docetaxel. Urology 78: 1131-1135, 2011

115. Kantoff PW, Higano CS, Shore ND, et al: Sipuleucel-T immunotherapy for castration-resistant prostate cancer. N Engl J Med 363: 411-422, 2010.

116. de Bono JS, Oudard S, Ozguroglu M, et al: Prednisone plus cabazitaxel or mitoxantrone for metastatic castration-resistan prostate cancer progressing after docetaxel treatment: a randomised open-label trial. Lancet 376: 1147-1154, 2010.

117. Yin L, Hu Q and Hartmann RW: Recent progress in pharmaceutical therapies for castration-resistant prostate cancer. Int J Mol Sci 14: 13958-13978, 2013.

118. Saad F, Hotte S, North S, et al: Randomized phase II trial of custirsen (OGX-011) in combination with docetaxel or mitoxantrone as second-line therapy in patients with metastatic castrate-resistant prostate cancer progressing after first-line docetaxel: CUOG trial P-06c. Clin Cancer Res 17: 5765-5773, 2011.

119. Hudes G, Tagawa ST, Whang YE, et al: A phase 1 study of a chimeric monoclonal antibody against interleukin-6, siltuximab, combined with docetaxel in patients with metastatic castrationresistant prostate cancer. Invest New Drugs 31: 669-676, 2013.

120. Di Lorenzo G, Figg WD, Fossa SD, et al: Combination of bevacizumab and docetaxel in docetaxel-pretreated hormonerefractory prostate cancer: a phase 2 study. Eur Urol 54: 1089-1094, 2008.

121. Kelly WK, Halabi S, Carducci M, et al: Randomized, doubleblind, placebo-controlled phase III trial comparing docetaxel and prednisone with or without bevacizumab in men with metastatic castration-resistant prostate cancer: CALGB 90401. J Clin Oncol 30: 1534-1540, 2012.

122. Adamo V, Noto L, Franchina T, et al: Emerging targeted therapies for castration-resistant prostate cancer. Front Endocrinol (Lausanne) 3: 73, 2012.

123. Galsky MD and Vogelzang NJ: Docetaxel-based combination therapy for castration-resistant prostate cancer. Ann Oncol 21: 2135-2144, 2010.

124. Beer TM, Ryan CW, Venner PM, et al: Intermittent chemotherapy in patients with metastatic androgen-independent prostate cancer: results from ASCENT, a double-blinded, randomized comparison of high-dose calcitriol plus docetaxel with placebo plus docetaxel. Cancer 112: 326-330, 2008. 